\title{
openheart FD-OCT and IVUS for detection of incomplete stent apposition in heavily calcified vessels: novel insights
}

\author{
David M Leistner, Ulf Landmesser, Georg M Fröhlich
}

To cite: Leistner DM, Landmesser U, Fröhlich GM. FD-OCT and IVUS for detection of incomplete stent apposition in heavily calcified vessels: novel insights. Open Heart 2015;2:e000292. doi:10.1136/openhrt-2015000292

Accepted 25 August 2015

\section{Linked}

- http://dx.doi.org/10. 1136/openhrt-2014-000225

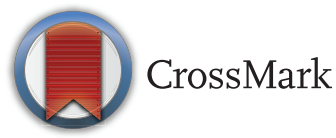

Department of Cardiology, Charité Universitätsmedizin Berlin (Campus Benjamin Franklin), Berlin, Germany

Correspondence to Dr Georg M Fröhlich; georg.froehlich@charite.de
In the present issue of Open Heart, Gudmundsdottir and colleagues compare two intracoronary imaging modalities, intravascular ultrasound (IVUS) and FD-optical coherence tomography (FD-OCT), in patients undergoing complex percutaneous coronary intervention (PCI) with rotablation for calcific coronary lesions. In particular, this study sought to detect incomplete stent apposition (ISA) using these different imaging modalities. ISA may play a role in the risk of target vessel failure, for example, stent thrombosis. ${ }^{1}$

Intracoronary imaging has become widely available with the advent of IVUS in the early 1990s. ${ }^{2}$ IVUS-derived images with an axial resolution down to $150 \mu \mathrm{m}$ have given novel insights into the clinical evolution of coronary artery disease and plaque composition. ${ }^{3}$ This technology was rapidly embraced by the interventional cardiology community, mainly to assess coronary lesions of intermediate significance in larger coronary arteries, to size the stent diameter or to monitor optimal stent deployment and exclude coronary dissections post-stenting. ${ }^{2}$ While this new intracoronary imaging fuelled enthusiasm, to date, limited data exist to demonstrate that IVUS-guided PCI translates into a superior clinical outcome with respect to incomplete stent apposition (table 1). However, a large observational analysis comparing IVUS-guided against angiography-guided PCI suggested that IVUS guidance was associated with a reduction in stent thrombosis, myocardial infarction and major adverse cardiac events within 1 year after DES implantation. ${ }^{4}$ Moreover, some moderately sized clinical studies suggested an improved performance if IVUS was used, particularly for complex PCI procedures involving the left main stem. ${ }^{5}$ There are several limitations inherent in this technology. First, the spatial resolution may be limited for optimal stent evaluation. Second, heavy calcification may cause artefacts and compromise image quality. And third, IVUS further increases procedural costs. $^{2}$ Current European Society of Cardiology guidelines suggest a class IIa recommendation for the use of IVUS to optimise stent implantation in selected patients, to assess severity of left main stem disease and optimise left main stenting, and to reveal mechanisms of stent failure (eg, stent thrombosis). ${ }^{6}$

The first coronary FD-OCT images in humans were published in 2002. ${ }^{7}$ A major advantage of this technology is indeed the higher resolution, so that FD-OCT allows for qualitative plaque assessment with respect to plaque cap thickness or rupture. ${ }^{8}$ However, definitions on plaque vulnerability by FD-OCT are still under development. FD-OCT was also referred to as 'virtual histology' due to its excellent axial resolution down to $15 \mu \mathrm{m} .^{3}$ This level of accuracy owes to emission of light of a near infrared spectrum (approximately $1300 \mathrm{~nm}$ ) and immediate acquisition of backscattering by the FD-OCT probe. ${ }^{9}$ Optimal image acquisition may only be achieved if red blood cells are cleared sufficiently from the vessel lumen during a flush with transparent contrast die. ${ }^{9}$ Given the low penetration depth (1.0$1.5 \mathrm{~mm}$ ) of near infrared light, only the inner vessel layers may be visualised with FD-OCT, while the whole vessel plaque burden can only be estimated with IVUS. ${ }^{9}$ On the other hand, heavy vessel calcification does not necessarily impact on image quality in FD-OCT. In summary, the ESC guidelines do recommend FD-OCT to assess mechanisms of stent failure (class IIa) and to optimise stent implantation in selected patients (class IIb). ${ }^{6}$

Gudmundsdottir and colleagues investigated both intracoronary imaging modalities in a subset of patients with heavily calcified coronary lesions who underwent rotablation and PCI. ${ }^{1}$ The primary outcome measure in this study was the detection of ISA to the 
Table 1 Association of IVUS-guided or OCT-guided PCI with outcome parameters

\begin{tabular}{|c|c|c|c|c|c|}
\hline Author (ref) & $\mathbf{n}$ & Type of stent & $\begin{array}{l}\text { Assessment } \\
\text { of ISA by }\end{array}$ & $\begin{array}{l}\text { Follow-up } \\
\text { (months) }\end{array}$ & $\begin{array}{l}\text { Association of ISA and } \\
\text { cardiovascular events }\end{array}$ \\
\hline Cook et $a l^{10}$ & 188 & SES/PES & IVUS & 8 & $\begin{array}{l}\text { YES (ISA highly prevalent in patients with } \\
\text { very late stent thrombosis }\end{array}$ \\
\hline Cook et $a l^{11}$ & 194 & SES/PES & IVUS & 8 & $\begin{array}{l}\text { YES (presence of ISA after DES associated } \\
\text { with higher risk AMI and very late stent } \\
\text { thrombosis }\end{array}$ \\
\hline Witzenbichler et $a \digamma^{4}$ & 8583 & DES & IVUS & 12 & YES (less ST, MI and MACE) \\
\hline Tanabe et al ${ }^{14}$ & 469 & PES/BMS & IVUS & 6 & NO \\
\hline Steinberg et $a l^{15}$ & 1580 & PES/BMS & IVUS & 9 & NO \\
\hline Hong et $a l^{16}$ & 557 & SES/PES & IVUS & 6 & NO \\
\hline Guagliumi et al ${ }^{17}$ & 21 & ZES & ОСТ & 6 & NO \\
\hline Kubo et $a l^{18}$ & 45 & SES & OCT & 9 & NO \\
\hline Guagliumi et $a l^{19}$ & 77 & $\begin{array}{l}\text { SES/PES/ } \\
\text { ZES/BMS }\end{array}$ & OCT & 6 & NO \\
\hline Guagliumi et al ${ }^{17}$ & 42 & EES & OCT & 6 & NO \\
\hline
\end{tabular}

vessel wall. ISA is defined as the lack of contact of stent struts with the vessel wall. ${ }^{3}$ This phenomenon may occur acutely: (1) due to underexpansion of the stent with insufficient inflation pressure; (2) following poor or late selection of stent size during follow-up; (3) which may then be due to thrombus resolution after Primary PCI or (4) because of insufficient radial force of the stent and consecutive recoil. ${ }^{3}$ The clinical relevance of improved detection of malapposed stent struts still needs to be better understood. Only several small studies investigated this subject with FD-OCT so far (table 1). However, two IVUS studies investigating first generation drug eluting stents found an association between ISA with very late stent thrombosis and myocardial infarction. ${ }^{10} 11$ This may be explained by the lower resolution of IVUS, where only significant levels of ISA may be detected, but not necessarily single stent strut malapposition, which is not relevant. One small study revealed ISA in $74 \%$ of patients presenting with late stent thrombosis. ${ }^{12}$ However, the majority of cases were declared as late-acquired ISA, so this likely could not be prevented by stent optimisation at baseline. Moreover, in-stent restenosis has been linked to ISA but existing data are rather limited. ${ }^{13}$

In the present manuscript, however, the clinical relevance of ISA was not the main focus. ${ }^{1}$ Of note, FD-OCT use in these highly calcified vessels allowed for improved detection of ISA as compared to IVUS. ${ }^{1}$ This finding is in line with previous studies and explained by the higher resolution of FD-OCT. Moreover, FD-OCT imaging triggered more intense postdilation, which reduced the extent of ISA from $34 \%$ of stent surface area to $19 \%^{1}$ in this patient group with rotablation, and heavy calcification where ISA is expected, postdilation with a non-compliant balloon, may actually be considered standard procedure. If FD-OCT should be repeated after postdilation and if further more intense postdilation might yield superior outcomes was not examined in the present study.

In essence, the authors present an interesting study suggesting that FD-OCT provides more detailed information as compared to IVUS and may be a valuable imaging modality in the setting of heavily calcified coronary lesions. However, all of the aforementioned potential downsides need to be carefully considered, and more data are needed to determine the clinical role of FD-OCT in detection of ISA and the impact of different degrees of ISA on clinical outcome.

\section{Contributors GMF and DML drafted the manuscript and UL revised it.}

Competing interests UL received honoraria or research grants from Orbus Neich, Terumo and St Jude.

Provenance and peer review Commissioned; internally peer reviewed.

Open Access This is an Open Access article distributed in accordance with the Creative Commons Attribution Non Commercial (CC BY-NC 4.0) license, which permits others to distribute, remix, adapt, build upon this work noncommercially, and license their derivative works on different terms, provided the original work is properly cited and the use is non-commercial. See: http:// creativecommons.org/licenses/by-nc/4.0/

\section{REFERENCES}

1. I G. Optical coherence tomography versus intravascular ultrasound to evaluate stent implantation in patients with calcific coronary artery disease. Open Heart 2015; $:$ m.

2. Nissen SE, Grines CL, Gurley JC, et al. Application of a new phased-array ultrasound imaging catheter in the assessment of vascular dimensions. In vivo comparison to cineangiography. Circulation 1990;81:660-6.

3. Attizzani GF, Capodanno D, Ohno $Y$ and, et al Mechanisms, pathophysiology, and clinical aspects of incomplete stent apposition. J Am Coll Cardiol 2014;63:1355-67.

4. Witzenbichler B, Maehara A, Weisz G, et al. Relationship between intravascular ultrasound guidance and clinical outcomes after drug-eluting stents: the assessment of dual antiplatelet therapy with drug-eluting stents (ADAPT-DES) study. Circulation 2014;129:463-70. 
5. Park SJ, Kim YH, Park DW, et al. Impact of intravascular ultrasound guidance on long-term mortality in stenting for unprotected left main coronary artery stenosis. Circ Cardiovasc Interv 2009;2:167-77.

6. Windecker S, Kolh P, Alfonso F, et al, Authors/Task Force members. 2014 ESC/EACTS Guidelines on myocardial revascularization: the Task Force on Myocardial Revascularization of the European Society of Cardiology (ESC) and the European Association for Cardio-Thoracic Surgery (EACTS)Developed with the special contribution of the European Association of Percutaneous Cardiovascular Interventions (EAPCI). Eur Heart J 2014;35:2541-619.

7. Jang IK, Bouma BE, Kang DH, et al. Visualization of coronary atherosclerotic plaques in patients using optical coherence tomography: comparison with intravascular ultrasound. J Am Coll Cardiol 2002;39:604-9.

8. Otsuka F, Joner M, Prati F, et al. Clinical classification of plaque morphology in coronary disease. Nat Rev Cardiol 2014;11:379-89.

9. Bezerra HG, Costa MA, Guagliumi G, et al. Intracoronary optical coherence tomography: a comprehensive review clinical and research applications. JACC Cardiovasc Interv 2009;2:1035-46.

10. Cook S, Eshtehardi P, Kalesan B, et al. Impact of incomplete stent apposition on long-term clinical outcome after drug-eluting stent implantation. Eur Heart J 2012;33:1334-43.

11. Cook S, Wenaweser $\mathrm{P}$, Togni $\mathrm{M}$, et al. Incomplete stent apposition and very late stent thrombosis after drug-eluting stent implantation. Circulation 2007;115:2426-34.

12. Lee CW, Kang SJ, Park DW, et al. Intravascular ultrasound findings in patients with very late stent thrombosis after either drug-eluting or bare-metal stent implantation. J Am Coll Cardiol 2010;55:1936-42.
13. Santos MC, Lin T, Barlis $P$. In-stent restenosis associated with stent malapposition: seven year optical coherence tomography findings. Int J Cardiol 2011;147:149-51.

14. Tanabe K, Serruys PW, Degertekin M, et al. Incomplete stent apposition after implantation of paclitaxel-eluting stents or bare metal stents: insights from the randomized TAXUS II trial. Circulation 2005;111:900-5.

15. Steinberg DH, Mintz GS, Mandinov L, et al. Long-term impact of routinely detected early and late incomplete stent apposition: an integrated intravascular ultrasound analysis of the TAXUS IV, V, and $\mathrm{VI}$ and TAXUS ATLAS workhorse, long lesion, and direct stent studies. JACC Cardiovasc Interv 2010;3:486-94.

16. Hong MK, Mintz GS, Lee CW, et al. Late stent malapposition after drug-eluting stent implantation: an intravascular ultrasound analysis with long-term follow-up. Circulation 2006;113:414-19.

17. Guagliumi G, Ikejima $\mathrm{H}$, Sirbu V, et al. Impact of drug release kinetics on vascular response to different zotarolimus-eluting stents implanted in patients with long coronary stenoses: the LongOCT study (Optical Coherence Tomography in Long Lesions). JACC Cardiovasc Interv 2011;4:778-85.

18. Kubo T, Imanishi T, Kitabata $\mathrm{H}$, et al. Comparison of vascular response after sirolimus-eluting stent implantation between patients with unstable and stable angina pectoris: a serial optical coherence tomography study. JACC Cardiovasc Imaging 2008;1:475-84.

19. Guagliumi G, Musumeci G, Sirbu V, et al. Optical coherence tomography assessment of in vivo vascular response after implantation of overlapping bare-metal and drug-eluting stents. JACC Cardiovasc Interv 2010;3:531-9. 